\title{
Needle Directed Pulse Spray Pharmacomechanical Thrombolysis for Acute Thrombosis of Dialysis Fistulas - Technique, Efficacy and Short Term Follow UP
}

\author{
Geda Anusha ${ }^{\circledR 1}$, Yugandhar Samireddypalle ${ }^{\circledR 2}$, Ranjith Kumar Vulchi ${ }^{\oplus 1}$, Sagar Dembla ${ }^{\circ}$, Pavithira Annamalai ${ }^{\odot 4}$, Sabarinath Eada ${ }^{\oplus 5}$, \\ Amitha Vikrama K S 6 \\ ${ }^{1}$ Post Graduate, Department of Radiology, Narayana medical college, Nellore, Andhra Pradesh, India, ${ }^{2}$ Senior resident, Interventional Radiologist, Department of \\ Radiology, Narayana medical college, Nellore, Andhra Pradesh, India, ${ }^{3}$ Senior Resident, Medical Gastroenterology, Narayana medical college, Nellore, Andhra Pradesh, \\ India, ${ }^{4}$ Junior Resident, Department of General Medicine, Mandya Institute of Medical Sciences, Mandya, Karnataka, India, ${ }^{5}$ Post Graduate, Department of Radiology, \\ Narayana medical college, Nellore, Andhra Pradesh, India, ${ }^{6} \mathrm{Head}$, Department of Radiology, Apollo Hospitals, Bangalore, Karnataka, India.
}

\section{Abstract}

Background: The incidence of end stage renal disease is on the rise and most of these patients are undergoing dialysis either through tunnelled /non tunnelled dialysis catheters or through arteriovenous fistulas/grafts. The dialysis grafts and fistulas have limited durability of about 3 years and are more prone for thrombosis and stenosis. Catheter directed interventions are successful in establishing flow in most of the thrombosed fistulas, but require dedicated Cath lab and tertiary care centre. Needle directed thrombolysis is a novel economical, safe technique for thrombolysis of dialysis fistulas and grafts. The aim of the studt is to review the technique, safety, efficacy of needle directed pulse spray pharmacomechanical thrombolysis of dialysis fistulas and grafts with short term follow up. Subjects and Methods: This was a prospective observational study done in department of Radio diagnosis, Narayana medical college, Nellore. Selectively 25 patients with thrombosed AV fistulas were referred from nephrology OPD for needle directed thrombolysis to our department from December 2018 to May 2019 . The procedure was performed on OPD basis in ultrasound procedure room. Regular Doppler follow up of patients is done up to 6 months. Results: Out of twenty five cases about seventeen cases $(68 \%)$ were successful in achieving adequate recanalization in single session. four cases (16\%) required repeat sessions of thrombolysis and were successful in second attempt. In four cases (16\%) there was failure in attaining adequate recanalization due to marked multisegment attenuation/flow limiting stenosis of the draining vein. Conclusion: Needle directed Pulse spray pharmacomechanical thrombolysis is a novel technique, which can be done bedside, under portable ultrasound guidance and is an economical procedure as no intervention hardware is required. Continuous monitoring allows procedure to be stopped at the earliest once there is optimal recanalization, minimizing the systemic side effects of thrombolytic agents.

Keywords: Connective Tissue Disorders, Thoracic Manifestations, Interstitial Lung Disease.

Corresponding Author: Yugandhar Samireddypalle, Senior resident, Interventional Radiologist, Department of Radiology, Narayana medical college, Nellore, Andhra Pradesh, India.

E-mail: drsushmapandey@gmail.com

Received: 15 December 2019

Revised: 24 January 2020

Accepted: 03 February 2020

Published: 29 April 2020

\section{Introduction}

There is increased incidence of end stage renal disease and the mainstay of management of these patients is through regular haemodialysis or peritoneal dialysis. Haemodialysis is much safer and more preferred to peritoneal dialysis. Haemodialysis is performed either through tunnelled /non tunnelled dialysis catheters or through arteriovenous fistulas/grafts. Based on age of kidney failure ,between $23 \%$ and $51 \%$ of patients after starting dialysis will have an additional life expectancy of 10 years. ${ }^{[1]}$ Longtime preservation of dialysis sites is important for prolonged management of patients due to limited vascular access sites.

Various advantages of Arteriovenous fistulas over synthetic grafts are less infections, better patency, low risk of vascular steal syndrome, and decreased morbidity rates due to the surgical intervention during shunt creation. ${ }^{[2]}$ The National Kidney Foundation Dialysis Outcomes Quality Initiative (NKFDOQI) clinical practice guidelines has recommended recently 
that, ultimately, $40 \%$ of patients undergoing haemodialysis, should have an arteriovenous fistula. ${ }^{[3]}$ These dialysis grafts and fistulas have limited durability of about 3 years and are more prone for thrombosis and stenosis.

Catheter directed interventions are successful in establishing flow in most of the thrombosed fistulas/grafts and are widely used techniques, but require dedicated Cath lab, investigations, a tertiary care centre and are expensive. Percutaneous needle directed thrombolysis is a novel economic, safe technique for thrombolysis of dialysis fistulas and grafts and has become a propitious and well established technique overseas after the evolution of novel pharmaco-mechanical pulse spray thrombolysis technique. ${ }^{[4,5]}$ This procedure can be performed as an OP procedure or bedside under ultrasound guidance and does not require CATH lab or high end equipment making it an economical technique compared to catheter guided interventions. In this technique, thrombolysis is achieved through placement of multiple small needles in the dialysis grafts or thrombosed veins. Balloon angioplasty or stent placement is performed after thrombolysis, if an underlying stenosis is detected.

The standard therapy for a thrombosed AVF traditionally followed is surgical repair. Frequently used procedures are surgical thrombectomy with underlying stenosis repair or novel creation of more proximal arteriovenous anastomosis. ${ }^{[6]} \mathrm{How}-$ ever, the surgical thrombectomy results are not satisfactory, with success rates varying from $28 \%$ to $73 \%{ }^{[7-9]}$ By surgical intervention only few thrombosed AVFs can be salvaged, ${ }^{[10]}$ and it has been recommended by many surgeons that for thrombosed AV fistulas salvage procedures are not to be attempted. So there is need of additional management options.

In recent researches it was found that for management of thrombosed native AV fistula by percutaneous needle thrombolysis is effective. ${ }^{[11-13]}$ There are multiple percutaneous methods for thrombolysis in fistulas. Currently used techniques are: mechanical thrombectomy with various devices, manual thromboaspiration, balloon maceration of the clot, bolus or pulse-spray infusion of thrombolytic agents, or a combination of any of these methods. Reported technical success rates range from $73 \%$ to $100 \%$ and primary and secondary patency rates at 6 months were $18 \% 81 \%$ and $44 \% 84 \%$, respectively. ${ }^{[1-13]}$

\section{Subjects and Methods}

This was a prospective observational study done in department of Radio diagnosis, Narayana medical college, Nellore. Patients with failed arteriovenous (AV) fistula access presented to the nephrology OPD. After initial Doppler evaluation, 25 patients with thrombosed AV fistulas were selected for needle directed thrombolysis from December 2018 to May 2019 , ranged in age from 11 to 70 years. We only performed thrombolysis for mature fistulas which have undergone at least 5 sessions of dialysis. All fistulas were side-to-end AVFs with 13 cases being brachiocephalic fistulas and 12 cases radio-cephalic fistulas. Fistula duration ranged from two to 31 months from the time of creation. The procedure was performed on OPD basis in ultrasound procedure room using all aseptic precautions. These patients were closely followed up for 2 to 3 days until complete recanalization is achieved and further, regular monthly Doppler follow up of patients is done up to 6 months post procedure.

\section{Inclusion criteria}

- Acute thrombosis of dialysis grafts within 72 hours of absence of thrill.

\section{Exclusion criteria}

- Virgin fistulas with absent thrill which have not been cannulated at least once for dialysis

- Thrombosed fistulas with venous pseudoaneuryms

- Thrombosed fistulas with draining vein diameter less than $3 \mathrm{~mm}$

- Patients with acute thrombosis of fistulas who haven't undergone dialysis for more than 48 hours.

- Patients with all contraindications to thrombolytic therapy.

\section{Procedure}

This procedure was done bedside. Written informed consent explaining in detail about the planned procedure was taken from patient before interventional procedure. Under all aseptic precautions multiple 26 Gauge needles (one and half inch length) were inserted at regular intervals along the thrombosed draining vein with their tips directing toward the AV fistula and far from the fistula site. Only when the position of needle was confirmed within the lumen of veins, the needles were connected to three-way stop cocks with a short connector.

Care was taken to avoiding entry of air bubbles into the system.

A thrombolytic solution was prepared by dissolving 5 lakh units of urokinase in $20 \mathrm{ml}$ of heparinised saline (2000U). Under ultrasound guidance, $0.5 \mathrm{ml}$ of this thrombolytic solution was injected forcefully into each of these needles with pressure. At the end of each session of injection, Doppler was performed to look for restoration of flow.

Procedure was stopped at the earliest, once there is satisfactory recanalization. The procedure is termed successful, if there is moderate recanalization of fistula with pulsatile flow on spectral Doppler. The patient is kept on low molecular weight heparin for 48 to 72 hours till resolution of residual clots and reappearance of thrill at fistula site. Post Doppler confirmation of complete recanalization, the patient is advised to undergo 


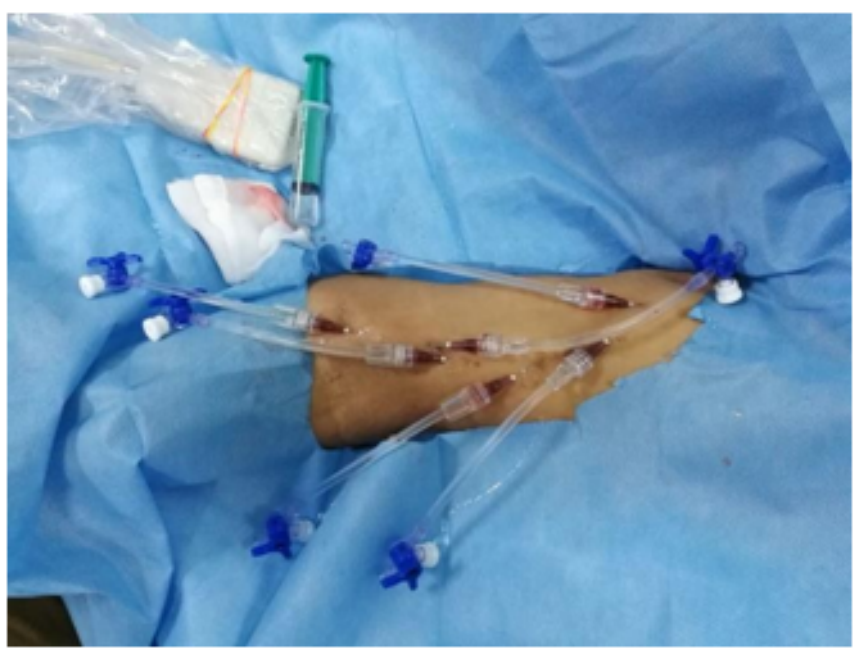

Figure 1: Image showing multiple $26 \mathrm{G}$ needles inserted into the draining cephalic vein of arteriovenous fistula (AVF) in the arm. Three-way stop cocks with connectors are connected to the needles.

\section{OUTCOMES OF OUR STUDY}

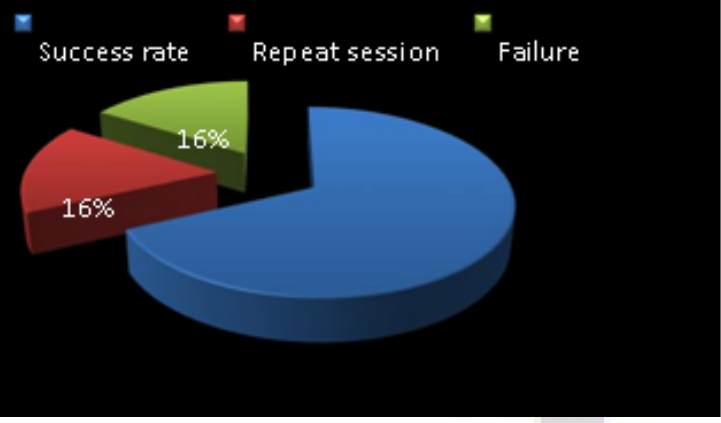

Figure 2: Pie diagram showing outcomes of our study

dialysis through the fistula. Any dialysis required till then, would be through temporary catheter inserted in central veins.

\section{Results}

In twenty five cases we have done, thirteen cases are brachiocephalic fistulas and twelve were radio cephalic fistulas, about seventeen cases $(68 \%)$ were successful in achieving adequate recanalization in single session, four cases $(16 \%)$ required repeat sessions of thrombolysis which on initial sessions did not recanalize optimally with rethrombosis, but were successfully recanalized in second attempt, done after 24 hours. In Four cases (16\%) there was failure in attaining adequate recanalization due to marked multisegment

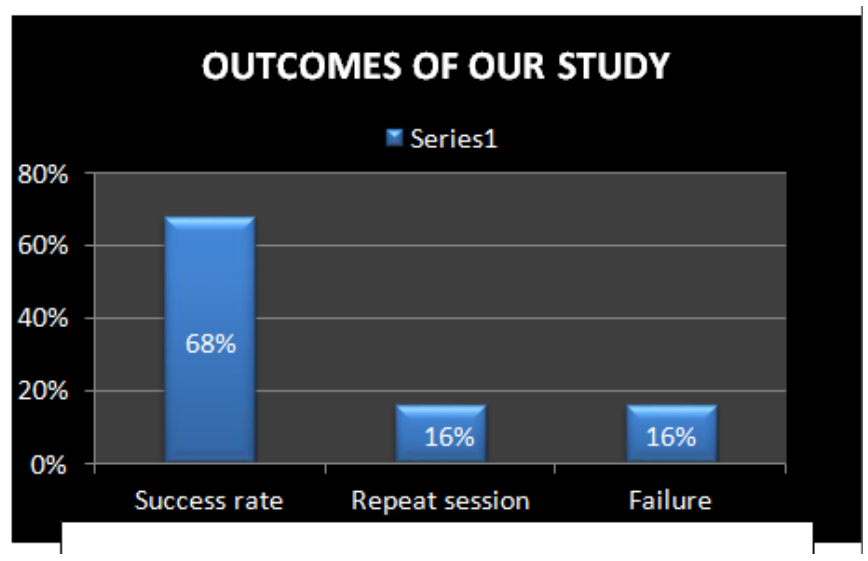

Figure 3: Bar diagram showing outcomes of our study

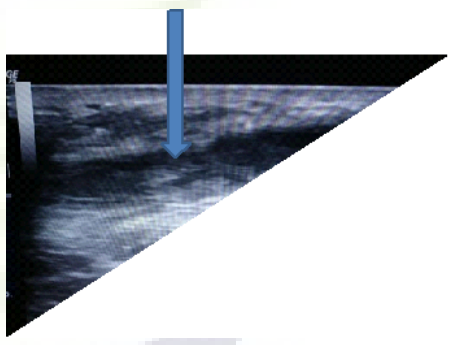

Figure 4: A Ultrasound demonstratinghypoechoic thrombus in the fistula

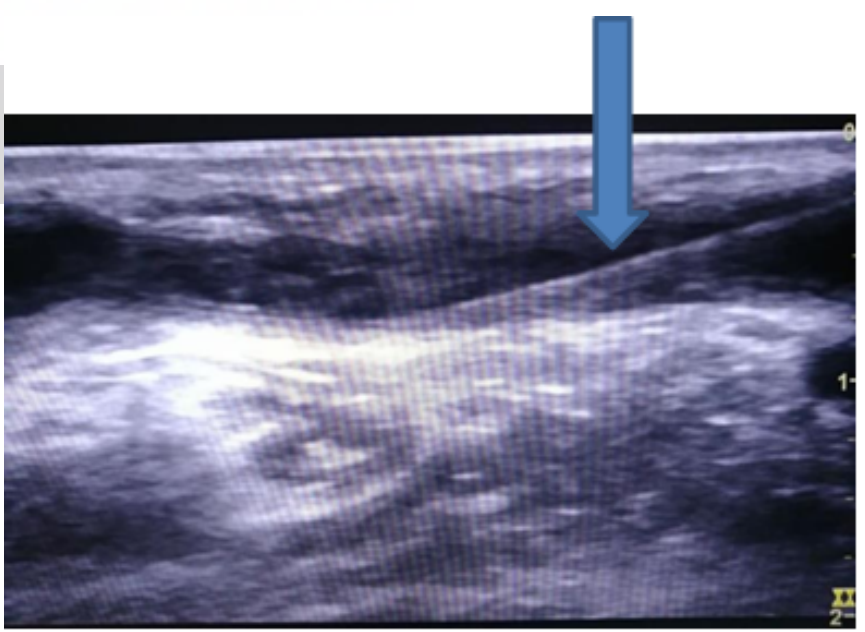

Figure 5: 26 Gauge needle inserted into the fistula

attenuation or flow limiting dissection/stenosis of the draining vein. In one of the cases, there was heavy feeding artery calcification with organised hematoma at the puncture points compressing the vein, which made the procedure technically 


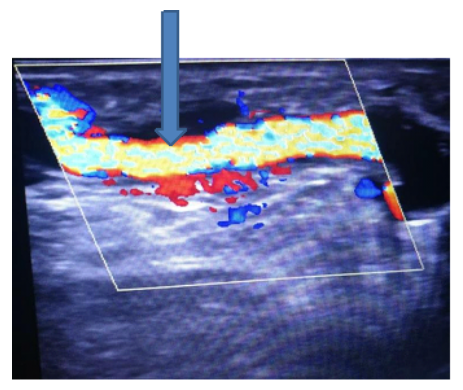

Figure 6: Follow up Doppler after two days showing complete resolution of the clots

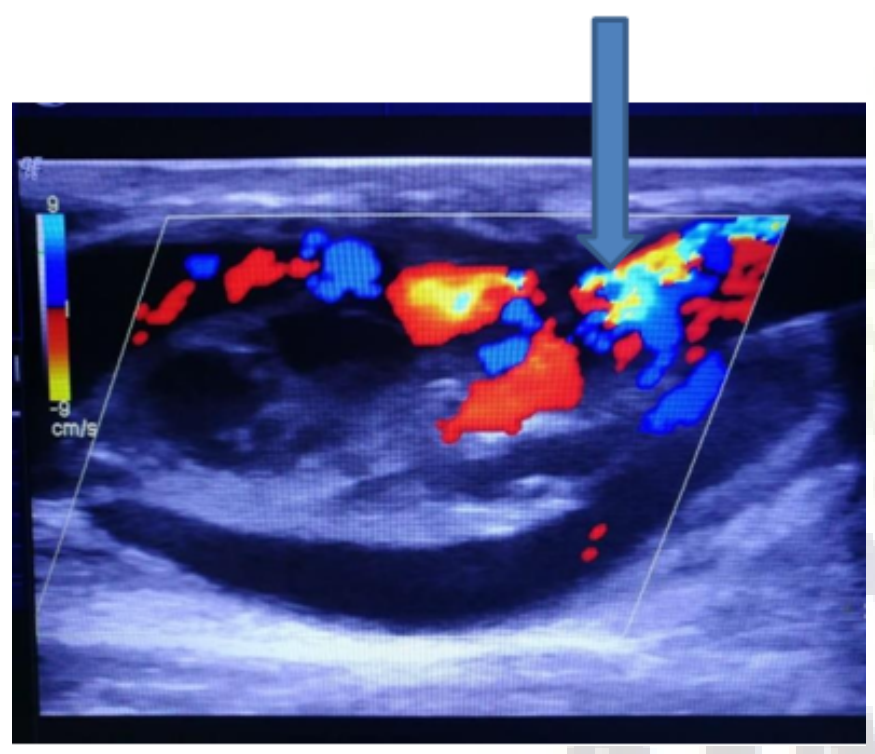

Figure 7: Procedure stopped at the earliest, once there is partial recanalization

difficult. In second case there was a short segment marked stenosis of mid cephalic vein, which was more clearly identified after Partial thrombolysis. The procedure was abandoned and fistuloplasty was done. In rest of the two cases there was development of dissection flap at proximal end of vein near fistula site with recurrent thrombosis.

\section{Illustrative Cases}

\section{Illustrative Case 1}

[Figure 4-6] Ultrasound and Doppler images in illustrative case

\section{Illustrative Case 2}

[Figure 7-9] Doppler images in illustrative case 2

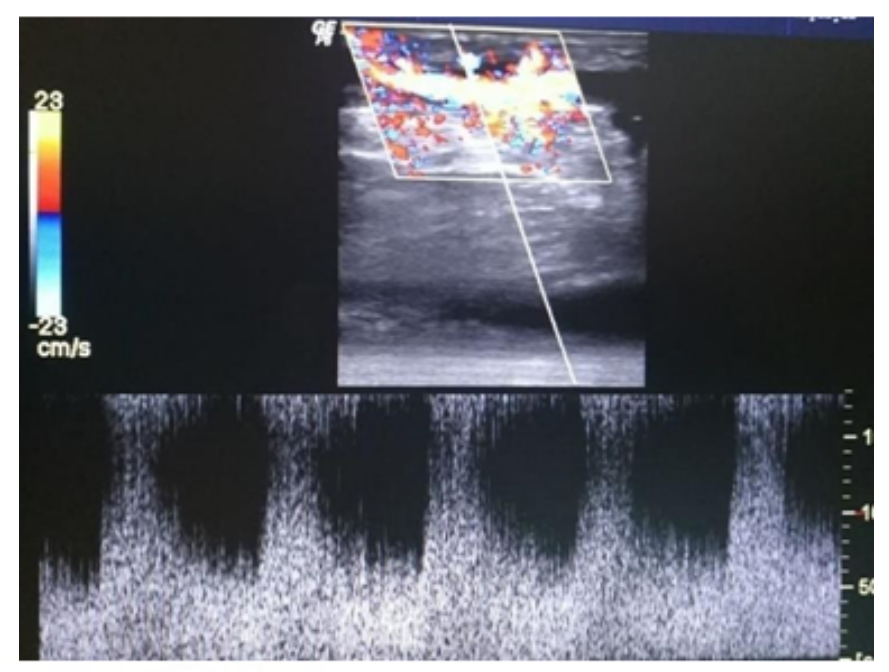

Figure 8: Follow up spectral Doppler after 48hours, demonstrating complete recanalization with turbulent flow

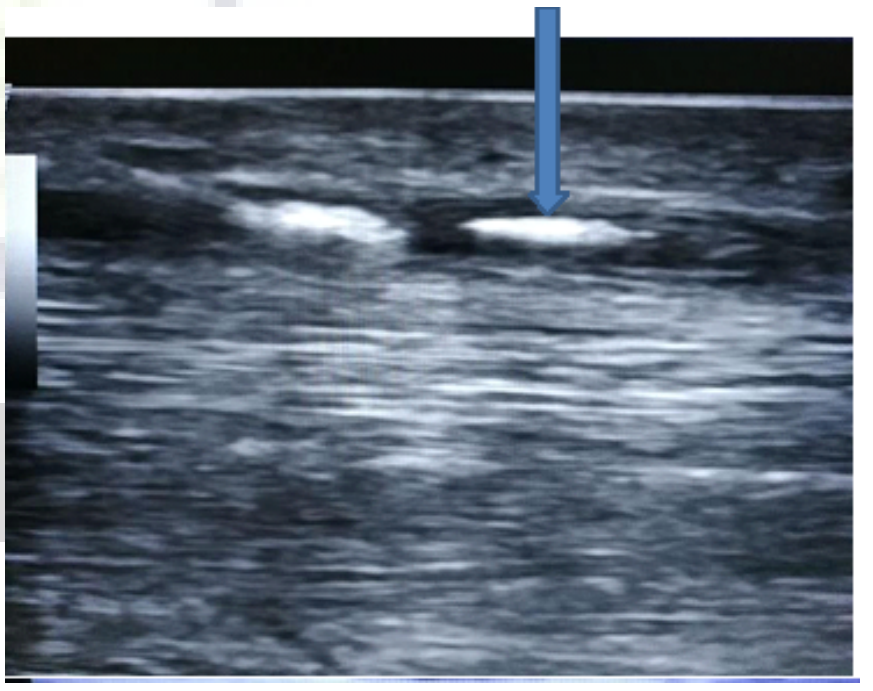

Figure 9: Echoes due to accidental injection of air into the draining vein, decreasing the optimal visualisation

\section{Discussion}

For thrombosed dialysis grafts and fistulas currently, the main treatment options are mechanical and pharmacomechanical thrombolysis Procedure time is shorter in mechanical thrombectomy than pharmacomechanical thrombectomy based on the results for treating the thrombosed dialysis grafts, but there were no considerable differences in the technical success rate, post procedural complications, and primary patency rates between the two types. ${ }^{[14,15]}$ The other disadvantage 
of mechanical thrombectomy, devices, except balloon angioplasty and manual thromboaspiration, are expensive and have high chances of vein wall damage. ${ }^{[15,16]}$ Although there is no clarity which method is better, there has been reduction in clot burden in fistula by administration of a lytic agent, such as urokinase. ${ }^{[17]}$

In the present study the primary mode of management for salvaging of thrombosed native fistulas is needle directed pulse-spray pharmacomechanical thrombolysis.

Few of the published studies showed that the primary therapeutic method for clot removal in thrombosed AV fistulas was mechanical thrombectomy by use of various mechanical thrombectomy devices, manual thromboaspiration, and balloon maceration of clot. ${ }^{[18]}$. Technical success rates of $76 \%$ $100 \%$ with primary patency rates of $18 \%-81 \%$ at six months and assisted primary or secondary patency rates of $60 \%-80 \%$ at six months have been reported in these studies.

Schon and Mishler, ${ }^{[12]}$ conducted a study of 16 thrombosed AVFs, by using pharmacomechanical thrombolysis with low dose urokinase or tissue plasminogen activator (tPA) bolus infusion along with external manual maceration of clots; the reported technical success rate was $94 \%$. Patency rates were not reported. In another study by Zaleski et al. ${ }^{[1]}$ in seventeen thrombosed fistulas, initial anastomotic angioplasty, bolus urokinase infusion for 1 minute, and balloon maceration of the clot were used for pharmacomechanical thrombolysis. They reported $82 \%$ technical success rate with $71 \%$ primary patency rates at six months and $64 \%$ at 12 months and at six and 12 months (excluding initial failures) $100 \%$ secondary rates. In another study done by Rajan et al. ${ }^{[13]}$ in which pharmacomechanical thrombolysis similar to our study was used in which 25 thrombosed AVFs were managed by pulsespray injection of urokinase or recombinant tPA along with with balloon maceration or a thrombectomy device to treat the clot, and a $77 \%$ technical success rate with primary and secondary patency rates of $28 \%$ and $44 \%$ at six months and $24 \%$ and $44 \%$ at 12 months, was reported.

Catheter directed thrombolysis requires a Cath-lab suite for positioning of infusion catheter. Prolonged infusion is usually required for several hours with intermittent Doppler or check angiograms. In addition, monitoring in HDU is mandatory during continuous thrombolytic infusion to monitor and detect any complication at the earliest. These procedures can be done in tertiary care centres with well-equipped lab and proper HDU care. Also, the cost factor for the intervention hardware and patient affordability has also to be considered. ${ }^{[19]}$

Needle directed Pulse spray pharmacomechanical thrombolysis is a novel technique, which can be done bedside, under portable ultrasound guidance. ${ }^{[20]}$ It is an economical procedure as no intervention hardware is required. Each aliquot of injection can be monitored under ultrasound guidance and the procedure can be stopped at the earliest, once there is recanalization.

This procedure requires proper intraluminal placement of needles at regular intervals. The proximal and distal needles have to be placed at the proximal and distal end of the thrombus as recanalization can be achieved only once there is both inflow and outflow. Each injection needs to be given forcefully for proper dissipation of the urokinase to achieve uniform thrombolysis. The procedure is stopped once there is optimal recanalization irrespective of clot burden. This is to prevent systemic infusion of urokinase. Low molecular weight heparin post procedure will prevent rethrombosis and it can be stopped once complete recanalization is achieved.

Thrombolysis is attempted upto 72 hours from the time of absence of thrill. In cases where last session of dialysis was more than 2 days ago, we strongly recommend dialysis through temporary catheter and attempt thrombolysis post dialysis. This is to reduce the systemic complications of thrombolytic agents. In such cases the time period can be extended up to 96 hours.

Length of thrombus is no limiting factor for needle directed thrombolysis. Thrombolysis have been successfully done for complete thrombosis of both draining cephalic as well as basilic veins with long segment of thrombus till the subclavian or axillary insertion. Extension of thrombus into the deep veins requires CDT (Catheter directed thrombolysis).

The procedure is termed failure, if there is no recanalization even after injecting 7.5lakh units of urokinase under one session or after injecting 5lakh units of urokinase each in two consecutive sessions of thrombolysis done 24 hours apart

The procedure is termed successful, if there is moderate recanalization of fistula with pulsatile flow on spectral Doppler. The patient is kept on heparin for 48to72hours till resolution of residual clots and reappearance of thrill at fistula site. Post Doppler confirmation of complete recanalization, the patient is advised to undergo dialysis through the fistula. Any dialysis required till then, would be through temporary catheter inserted in central veins.

Proper patient selection is important for success of the procedure. We only performed thrombolysis for mature fistulas which have undergone at least 5 sessions of dialysis. Virgin fistulas were excluded in our study. Care should be taken for exclusion of air into the system as procedure is done under ultrasound guidance.

Flow limiting stenosis appears to be a poor prognostic factor for success of the procedure as these patients ultimately require fistuloplasty. In our study 25 cases have been thrombolysis till now under ultrasound guidance and have been followed up for 6 Months, seventeen cases were successful, and in four cases, thrombolysis was successful after second session of thrombolysis, done after 24 hours. Four cases were 
unsuccessful, due to technical difficulty and flow limiting stenosis/dissection. So in our study there was a success rate of $68 \%$, with $16 \%$ cases requiring second session and failure rate in $16 \%$ cases

\section{Conclusion}

Needle directed Pulse spray pharmacomechanical thrombolysis is a novel technique, which can be done bedside, under portable ultrasound guidance, it's an economical procedure compared to catheter guided interventions, as in this procedure no intervention is required, Continuous monitoring allows procedure to be stopped at the earliest once there is recanalization, minimizing the systemic side effects of thrombolytic agents. Careful patient selection is required for increasing the success rate of the procedure. Larger studies are further required to prove its safety and to compare its efficacy with catheter directed thrombolysis.

\section{References}

1. Mailloux LU, Bellucci AG, Napolitano B, Mossey T, Wilkes BM, Bluestone PA. Survival estimates for 683 patients starting dialysis from 1970 through 1989: identification of risk factors for survival. Clin Nephrol. 1994;42(2):127-135.

2. Chazan JA, London MR, Pono LM. Long-Term Survival of Vascular Accesses in a Large Chronic Hemodialysis Population. Nephron. 1995;69(3):228-233. Available from: https://dx.doi.org/10.1159/000188461.

3. I. NKF-K/DOQI Clinical Practice Guidelines for Hemodialysis Adequacy: update 2000. Am J Kidney Dis. 2001;37(Suppl. 1):7-64. Available from: https://doi.org/10.1016/s02726386(01)70005-4.

4. Cooper SG. Pulse-spray thrombolysis of thrombosed hemodialysis grafts with tissue plasminogen activator. Am J Roentgenol. 2003;180:1063-1066. Available from: https://dx.doi.org/10. 2214/ajr.180.4.1801063.

5. Bookstein JJ, Fellmeth B, Roberts A, Valji K, Davis G, Machado T. Pulsed-spray pharmacomechanical thrombolysis: preliminary clinical results. Am J Roentgenol. 1989;152(5):1097-1100. Available from: https://dx.doi.org/10. 2214/ajr.152.5.1097.

6. Palder SB, Kirkman RL, Whittemore AD, Hakim RM, Lazarus JM, Tilney NL. Vascular Access for Hemodialysis Patency Rates and Results of Revision. Ann Surg. 1985;202(2):235239. Available from: https://dx.doi.org/10.1097/00000658198508000-00015.

7. Burger H, Kluchert BA, Kootstra G, Kitslaar PJ, Ubbink DT. Survival of arteriovenous fistulas and shunts for haemodialysis. Eur J Surg. 1995;161(5):327-334.

8. Schwab SJ, Raymond JR, Saeed M, Newman GE, Dennis PA, Bollinger RR. Prevention of hemodialysis fistula thrombosis. Early detection of venous stenoses. Kidney Int. 1989;36(4):707-711. Available from: https://dx.doi.org/10. 1038/ki.1989.250.
9. Riordan S, Frawley J, Gray L, Niesche J. Primary access surgery for long-term haemodialysis. ANZ J Surg. 1994;64(11):763-767. Available from: https://dx.doi.org/10. 1111/j.1445-2197.1994.tb04535.x.

10. Kumpe DA, Cohen MAH. Angioplasty/thrombolytic treatment of failing and failed hemodialysis access sites: Comparison with surgical treatment. Prog Cardiovasc Dis. 1992;34(4):263-278. Available from: https://dx.doi.org/10. 1016/0033-0620(92)90021-q.

11. Zaleski GX, Funaki B, Kenney S, Lorenz JM, Garofalo R. Angioplasty and Bolus Urokinase Infusion for the Restoration of Function in Thrombosed Brescia-Cimino Dialysis Fistulas. J Vasc Interv Radiol. 1999;10(2):129-136. Available from: https://dx.doi.org/10.1016/s1051-0443(99)70454-9.

12. Schon D, Mishler R. Salvage of occluded autologous arteriovenous fistulae. Am J Kidney Dis. 2000;36(4):804-810. Available from: https://dx.doi.org/10.1053/ajkd.2000.17671.

13. Rajan DK, Clark TWI, Simons ME, Kachura JR, Sniderman K. Procedural Success and Patency after Percutaneous Treatment of Thrombosed Autogenous Arteriovenous Dialysis Fistulas. J Vasc Interv Radiol. 2002;13(12):1211-1218. Available from: https://dx.doi.org/10.1016/s1051-0443(07)61967-8.

14. Middlebrook MR, Amygdalos MA, Soulen MC, Haskal ZJ, Shlansky-Goldberg RD, Cope C, et al. Thrombosed hemodialysis grafts: percutaneous mechanical balloon declotting versus thrombolysis. Radiology. 1995;196(1):73-77. Available from: https://dx.doi.org/10.1148/radiology.196.1.7784593.

15. Gibbens DT, Triolo J, Yu T, Depalma J, Iglasias J, Castner D. Contemporary treatment of thrombosed hemodialysis grafts. Tech Vasc Interv Radiol. 2001;4:122-126.

16. Sofocleous CT, Cooper SG, Schur I, Patel RI, Iqbal A, Walker S. Retrospective Comparison of the Amplatz Thrombectomy Device with Modified Pulse-Spray Pharmacomechanical Thrombolysis in the Treatment of Thrombosed Hemodialysis Access Grafts. Radiology. 1999;213(2):561-567. Available from: https://dx.doi.org/10.1148/radiology.213.2.r99nv32561.

17. Kinney TB, Valji K, Rose SC, Yeung DD, Oglevie SB, Roberts AC. Pulmonary Embolism from PulseSpray Pharmacomechanical Thrombolysis of Clotted Hemodialysis Grafts: Urokinase versus Heparinized Saline. J Vasc Interv Radiol. 2000;11(9):1143-1152. Available from: https://dx.doi.org/10. 1016/s1051-0443(07)61355-4.

18. Turmel-Rodrigues L, Pengloan J, Rodrigue H, Brillet G, Lataste A, Pierre D. Treatment of failed native arteriovenous fistulae for hemodialysis by interventional radiology. Kidney Int. 2000;57(3):1124-1140. Available from: https://dx.doi.org/10. 1046/j.1523-1755.2000.00940.x.

19. Vikrama KA, Srivalli N, Venkataramana RS. USG-guided needle-directed pulse-spray pharmaco-mechanical thrombolysis of hemodialysis grafts/fistula: A novel technique. Indian J Radiol Imaging. 2015;25(3):244-244. Available from: https: //dx.doi.org/10.4103/0971-3026.161442.

20. Vasanthraj P, Bandi VK, Sai V, Shekar M. Pulse-Spray Pharmacomechanical Thrombolysis of Native Arteriovenous Fistulas and Grafts under Ultrasound Guidance: Our Initial Experience. J Clin Interv Radiol. 2016;01:46-48. Available from: https://dx.doi.org/10.1055/s-0036-1597840. 
Copyright: (C) the author(s), 2020. It is an open-access article distributed under the terms of the Creative Commons Attribution License (CC BY 4.0), which permits authors to retain ownership of the copyright for their content, and allow anyone to download, reuse, reprint, modify, distribute and/or copy the content as long as the original authors and source are cited.

How to cite this article: Anusha G, Samireddypalle Y, Vulchi RK, Dembla S, Annamalai P, Eada S, Vikrama K S A. Needle Directed Pulse Spray Pharmacomechanical Thrombolysis for Acute Thrombosis of Dialysis Fistulas - Technique, Efficacy and Short Term Follow UP. Asian J. Med. Radiol. Res. 2020;8(1): 14-20.

DOI: dx.doi.org/10.47009/ajmrr.2020.8.1.3

Source of Support: Nil, Conflict of Interest: None declared. 